\title{
Tratamento pós-colheita com cálcio e microrganismos para controle da podridão-mole em tomate
}

\author{
Andréa M.A. Gomes ${ }^{1}$; Elineide B. Silveira ${ }^{2}$; Rosa L.R. Mariano ${ }^{1,3}$ \\ Universidade Federal Rural de Pernambuco, 52171-900 Recife-PE; ${ }^{1}$ Depto. Agronomia, Área de Fitossanidade; E-mail: \\ andreamagomes@hotmail.com; ${ }^{2}$ Depto. Biologia, Área de Microbiologia; E-mail: elineidebs@yahoo.cm.br, ${ }^{3}$ Bolsista CNPq.
}

\section{RESUMO}

Visando o controle da podridão-mole causada por Pectobacterium carotovorum subsp. carotovorum (Pcc) em tomate, foram avaliadas três fontes de cálcio $\left[\mathrm{CaCl}_{2}, \mathrm{Ca}\left(\mathrm{CO}_{3}\right)_{2} \mathrm{e} \mathrm{Ca}\left(\mathrm{SO}_{4}\right)_{2}\right]$, nas concentrações de $1 ; 2 ; 4 ; 6$; e $8 \%(\mathrm{p} / \mathrm{v})$, aplicadas pelo método de infiltração a vácuo. A inoculação do patógeno foi realizada 24 horas após o tratamento com cálcio, pela deposição de $10 \mathrm{ml}$ de uma suspensão bacteriana com concentração de $10^{8} \mathrm{UFC} / \mathrm{ml}$, sobre ferimentos artificiais nos frutos tratados. A incubação foi feita em câmara úmida (umidade relativa de $92 \pm 4 \%$ ) e a avaliação realizada $48 \mathrm{~h}$ após, medindo-se o diâmetro da lesão em sentidos diametralmente opostos, e calculando-se a porcentagem de redução da severidade da doença (RSD) em relação à testemunha. A melhor fonte e concentração de cálcio foi $\mathrm{CaCl}_{2}$ a $8 \%$ que reduziu a severidade da doença em $69,5 \%$. Foram avaliados também os microrganismos Rhodotorula sp. (LD-19) e Pseudomonas sp. fluorescente (P-2) isoladamente e associados ao $\mathrm{CaCl}_{2}$ a $8 \%$. O tratamento dos frutos com os microrganismos foi realizado depositando-se $10 \mathrm{ml}$ das suspensões $\left(\mathrm{DO}_{580}=0,7\right)$ sobre os ferimentos 24 horas após a aplicação do cálcio e duas horas antes da inoculação de Pcc. Houve diferença significativa entre os tratamentos, destacando-se a combinação $\mathrm{CaCl}_{2}$ a $8 \%$ + LD19, com RSD\% de 93\%. Os isolados P-2 e LD-19 aplicados isoladamente, apresentaram baixos percentuais de RSD.

Palavras-chave: Pectobacterium carotovorum subsp. carotovorum, controle biológico, controle integrado, Rhodotorula sp., Pseudomonas sp. fluorescente, cálcio.

\begin{abstract}
Postharvest treatments with calcium and microorganisms to control soft rot in tomato
\end{abstract}

The effect of three calcium sources $\left[\mathrm{CaCl}_{2}, \mathrm{Ca}\left(\mathrm{CO}_{3}\right)_{2}\right.$ and $\mathrm{Ca}$ $\left.\left(\mathrm{SO}_{4}\right)_{2}\right]$ at $1 ; 2 ; 4 ; 6$ and $8 \%(\mathrm{w} / \mathrm{v})$ were evaluated on control of soft rot caused by Pectobacterium carotovorum subsp. carotovorum (Pcc) in tomato fruits. The calcium sources were applied using vacuum infiltration. Fruits were inoculated with pathogen $24 \mathrm{~h}$ later by deposition of $10 \mathrm{ml}$ of a bacterial suspension containing $10^{8} \mathrm{CFU} /$ $\mathrm{ml}$, on artificial wounds. Fruits were incubated in a moist chamber at $92 \pm 4 \%$ relative humidity during $48 \mathrm{~h}$ and evaluated by measuring the lesion diameter in two opposite sides. The disease severity reduction (DSR) was calculated in relation to the control with calcium application. The best calcium source and concentration was $\mathrm{CaCl}_{2}$ $8 \%$ which reduced the disease severity by $69.5 \%$. The antagonists Rhodotorula sp. (LD-19) and a fluorescent Pseudomonas sp. (P-2) were tested separately and along with $\mathrm{CaCl}_{2} 8 \%$. The antagonist was applied by pouring $10 \mathrm{ml}$ of suspensions $\left(\mathrm{DO}_{580}=0.7\right)$ on the wounds $24 \mathrm{~h}$ after calcium treatment and $2 \mathrm{~h}$ before Pcc inoculation. The difference was significant among treatments and, the combination $\mathrm{CaCl}_{2} 8 \%+\mathrm{LD} 19$ showed $90 \%$ DSR. Isolates P-2 and LD-19 applied separated showed lower percentage of DSR.

Keywords: Pectobacterium carotovorum subsp. carotovorum, biological control, integrated control, Rhodotorula sp., fluorescent Pseudomonas sp, calcium.

\section{(Recebido para publicação em 26 de abril de 2004 e aceito em 4 de janeiro de 2005)}

$\mathrm{F}$ rutas e hortaliças são suscetíveis ao ataque de vários patógenos após a colheita. Mesmo quando o transporte e armazenamento são realizados de maneira adequada, verificam-se perdas de 5 a $10 \%$ da produção. Entretanto os prejuízos podem ser totais quando decorrentes de infecções muito severas ou dos danos provocados por armazenamento inadequado (Eckert, 1991). Os fatores hospedeiro, patógeno e ambiente, influenciam largamente o desenvolvimento de doenças pós-colheita.

No Brasil e em outros países é muito comum, no campo ou no período póscolheita, a ocorrência de podridão-mole em hortaliças, causada por Pectobacterium carotovorum subsp. carotovorum (Jones) Hauben et al. (sin.
Erwinia carotovora subsp. carotovora) (Jabuonski et al., 1986; Kurozawa e Pavan, 1997). O controle desta doença é dificultado, devido à capacidade de adaptação do patógeno a uma larga faixa de temperatura que o mantém viável por longos períodos, bem como à habilidade de sobreviver saprofiticamente nos tecidos infectados (De Boer et al., 1979; Xu e Gross, 1986). Métodos alternativos de controle efetivo para essa doença vêm sendo pesquisados, destacando-se a utilização do tratamento póscolheita com cálcio, bem como o uso de microrganismos antagonistas, tais como leveduras e Pseudomonas spp. fluorescentes (Melo et al., 1995).

A aplicação de sais de cálcio em frutos tem papel importante na redução de desordens fisiológicas, retardamento na senescência e inibição de podridões póscolheita (Conway et al., 1988, 1992; Sharples e Johnson, 1977). A habilidade do cálcio em reduzir o desenvolvimento de doenças pós-colheita em frutos tem sido atribuída, principalmente, à ligação deste íon às pectinas presentes na parede celular do fruto, resultando no decréscimo da habilidade das enzimas pectinolíticas produzidas pelo patógeno em degradar a parede celular (Conway et al., 1988).

A utilização de leveduras e bactérias no controle de podridões pós-colheita tem sido estudada por vários pesquisadores (Janisiewicz e Roitman, 1988; McLaughlin et al., 1990, 1992; Melo et al., 1995; Sanhueza, 1998), existindo os 
produtos comerciais Aspire ${ }^{\circledR}$ e Bio-save $110^{\circledR}$, à base de Candida oleophila I-182 e Pseudomonas syringae, respectivamente, para o controle de diversas doenças fúngicas em citros, cereja, batata e frutas de caroço (APS, 2002).

O efeito benéfico da combinação de cálcio com agentes de biocontrole já foi confirmado (Janisiewicz et al., 1998), e pode ser o resultado de diferentes interações entre íons de cálcio e o hospedeiro, o patógeno ou o microrganismo.

Considerando a importância econômica da podridão-mole e visando reduzir as perdas causadas durante o transporte, armazenamento e comercialização de tomate, este trabalho teve como objetivo avaliar o efeito do cálcio, Rhodotorula sp. e Pseudomonas sp. fluorescente no controle da infecção causada por $P$. carotovorum subsp. carotovorum.

\section{MATERIAL E MÉTODOS}

\section{Obtenção do fitopatógeno e teste de patogenicidade}

O isolado de $P$. carotovorum subsp. carotovorum (Pcc) foi obtido da coleção de microrganismos do Laboratório de Fitobacteriologia da Universidade Federal Rural de Pernambuco, sendo proveniente de frutos de tomate com infecção natural, estando preservado em água de torneira esterilizada.

$\mathrm{O}$ teste de patogenicidade foi realizado introduzindo-se a ponta de um palito esterilizado, após tocar em uma colônia de Pcc, em tomates sadios (Takatsu et al., 1981). Os frutos foram mantidos em câmara úmida (umidade relativa de $92 \pm 4 \%$ ) por 48 horas, até o aparecimento dos sintomas típicos da doença, procedendo-se ao reisolamento do patógeno.

Efeito do cálcio no controle da podridão-mole

Como fontes de cálcio foram avaliadas cloreto de cálcio $\left(\mathrm{CaCl}_{2}\right)$, carbonato de cálcio $\left[\mathrm{Ca}\left(\mathrm{CO}_{3}\right)_{2}\right]$ e sulfato de cálcio $\left[\mathrm{Ca}\left(\mathrm{SO}_{4}\right)_{2}\right]$, nas concentrações de $1 ; 2 ; 4 ; 6$ e $8 \%(\mathrm{p} / \mathrm{v})$, aplicadas pelo método de infiltração à vácuo. Os tomates foram lavados em água corrente com sabão, imersos em solução de hipoclorito de sódio $0,7 \%$ por 2 minutos, lavados três vezes com água desti- lada esterilizada (ADE) e colocados em câmara de fluxo laminar (TROX ${ }^{\circledR}$, modelo FLH) para secagem por três horas. Em seguida, os frutos foram submetidos à infiltração a vácuo que consistiu na imersão em suspensão contida em beaker, o qual foi colocado em dessecador acoplado à bomba de vácuo. Fez-se o vácuo a $40 \mathrm{~cm}$ de $\mathrm{Hg}$ por dois minutos, sendo os frutos postos para secar em condições de laboratório $\left(25 \pm 2^{\circ} \mathrm{C}\right)$. Após 24 horas, foram marcados quatro círculos na superfície dos frutos, dois em cada extremidade, e efetuados cinco ferimentos ( $2 \mathrm{~mm}$ de profundidade) eqüidistantes em cada área, com o auxílio de um alfinete entomológico. Sobre os ferimentos foi depositada uma gota de $10 \mathrm{ml}$ da suspensão de Pcc em ADE contendo espalhante adesivo Tween $80(0,05 \%)$. O patógeno foi cultivado por 24 horas em meio ágar nutritivo-dextrose-extrato de levedura NYDA (Pusey e Wilson, 1984) e a suspensão teve concentração ajustada para $10^{8} \mathrm{UFC} / \mathrm{ml}$ em fotocolorímetro a 580 nm. Os frutos foram incubados em câmara úmida (umidade relativa de $92 \pm 4 \%$ ) conforme metodologia descrita por Melo et al. (1995) e mantidos em condições de laboratório $\left(25 \pm 2^{\circ} \mathrm{C}\right)$. As testemunhas foram tratadas apenas com ADE e inoculadas com o fitopatógeno. O delineamento experimental foi inteiramente casualizado em arranjo fatorial de $3 \times 5$ +1 , representado por 3 fontes e 5 concentrações de cálcio, e uma testemunha. Foram utilizadas quatro repetições, sendo a unidade experimental constituída por um fruto com quatro áreas de inoculação.

A avaliação foi realizada 48 horas após a inoculação, medindo-se os diâmetros das lesões em sentidos diametralmente opostos e, calculandose a redução da severidade da doença (RSD) em relação à testemunha, pela fórmula adaptada de Edginton et al. (1971): RSD $\%=[($ DLT - DLTr $) / D L T]$ x 100 , onde DLT $=$ diâmetro da lesão na testemunha, DLTr $=$ diâmetro da lesão no tratamento.

Efeito da interação cálcio e microrganismos no controle da podridão-mole

Um isolado de Rhodotorula sp. (LD19) e um de Pseudomonas sp. fluorescente (P-2), selecionados previamente como potenciais agentes de biocontrole a Pcc em frutos de pimentão (Melo et al.,1995), foram associados ao cloreto de cálcio a $8 \%$ aplicado em tomates pelo método infiltração à vácuo. $\mathrm{O}$ tratamento com os microrganismos foi realizado 24 horas após a aplicação do cálcio e duas horas antes da inoculação de Pcc, depositando-se $10 \mathrm{ml}$ das suspensões $\left(\mathrm{DO}_{580}=0,7\right)$ sobre os ferimentos. A infiltração à vácuo com $\mathrm{CaCl}_{2}$, a inoculação do fitopatógeno e a avaliação foram realizadas conforme metodologia já descrita. O delineamento experimental foi inteiramente casualizado com seis tratamentos $\left(\mathrm{CaCl}_{2}, \mathrm{P}-2, \mathrm{LD}-19, \mathrm{CaCl}_{2}+\mathrm{P}-2\right.$, $\mathrm{CaCl}_{2}+\mathrm{LD}-19$ e $\left.\mathrm{CaCl}_{2}+\mathrm{P}-2+\mathrm{LD}-19\right)$ e seis repetições, sendo a unidade experimental constituída por um fruto com quatro áreas de inoculação.

Os dados obtidos foram submetidos à análise de variância e as médias comparadas pelo teste de Tukey a $5 \%$ de significância estatística.

\section{RESULTADOS E DISCUSSÃO}

A infiltração a vácuo mostrou-se eficiente na aplicação de diferentes fontes de cálcio em diferentes concentrações na redução da severidade da podridãomole em tomate. Este método também já foi empregado com sucesso no tratamento pós-colheita de frutos visando o controle de podridões causadas por Penicillium expansum e Botrytis cinerea em maçã (Conway et al., 1992), de $P$. carotovorum subsp. atrosepticum em batata (McGuire e Kelman, 1984; Conway et al., 1992) e de $P$. carotovorum subsp. carotovorum em pimentão (Melo et al., 1995).

Todas as fontes e concentrações de cálcio avaliadas foram eficientes na RSD de Pcc, destacando-se a aplicação de $\mathrm{CaCl}_{2}$ a $8 \%$ com redução da doença de $69,5 \%$, embora sem diferir significativamente $(\mathrm{P}=0,05)$ das concentrações 1 e 4\% (Tabela 1). Conway et al. (1992) relataram a eficiência da infiltração a vácuo de $\mathrm{CaCl}_{2}$ a $8 \%$, que reduziu em $25 \%$ o apodrecimento pós-colheita de maçã e batata. Este método de aplicação de cálcio, segundo McGuire e Kelman (1984), é o mais eficiente no controle da podridão de Pectobacterium 
Tabela 1. Efeito de fontes e concentrações de cálcio, aplicados por infiltração a vácuo, no controle de Pectobacterium carotovorum subsp. carotovorum em tomate, avaliado pela porcentagem de redução da severidade da doença (RSD). Recife, UFRPE, 2002.

\begin{tabular}{llrrrc}
\hline \multirow{2}{*}{$\begin{array}{l}\text { Fonte de } \\
\text { cálcio }\end{array}$} & \multicolumn{5}{c}{ Concentração de cálcio (\%) } \\
\cline { 2 - 6 } & $\mathbf{1}$ & $\mathbf{5}$ & $\mathbf{4}$ & $\mathbf{6}$ \\
\hline$n$ & $43,56 \mathrm{aAB}$ & $40,00 \mathrm{aB}$ & $42,20 \mathrm{aAB}$ & $30,10 \mathrm{aB}$ & $69,46 \mathrm{aA}$ \\
$\mathrm{CaCl}_{2}$ & $47,45 \mathrm{aA}$ & $4,01 \mathrm{bB}$ & $28,22 \mathrm{abAB}$ & $5,22 \mathrm{aB}$ & $27,87 \mathrm{bAB}$ \\
$\mathrm{CaCO}_{4}$ & $10,20 \mathrm{bA}$ & $16,40 \mathrm{abA}$ & $11,16 \mathrm{bA}$ & $15,80 \mathrm{aA}$ & $5,32 \mathrm{bA}$ \\
\hline
\end{tabular}

*Médias seguidas da mesma letra minúscula na coluna e maiúscula na linha, não diferem estatisticamente entre si, pelo teste de Tukey $(\mathrm{P}=0,05)$. C.V. $=15,4 \%$.

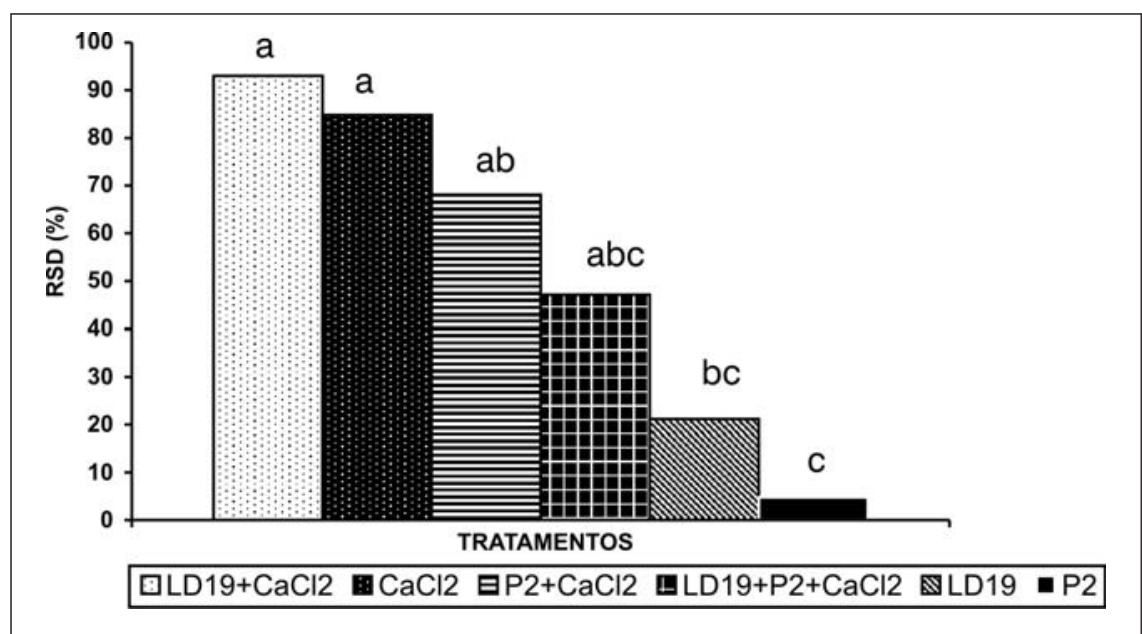

Figura 1. Efeito da interação de cálcio $\left(\mathrm{CaCl}_{2}\right.$ a $\left.8 \%\right)$ com Rhodotorula sp. (LD-19) e Pseudomonas sp. fluorescente (P-2) no controle de Pectobacterium carotovorum subsp. carotovorum em tomate, avaliado pela porcentagem de redução da severidade da doença (RSD). Recife, UFRPE, 2002.

em batata. Esses autores verificaram que $\mathrm{Ca}\left(\mathrm{NO}_{3}\right)_{2}$, nas concentrações de 0,$1 ; 0,6$ e $1,2 \%$, reduziu a severidade da podridão-mole em batata causada por $P$. carotovorum subsp. atrosepticum, em 58,$3 ; 83,9$ e $100 \%$, respectivamente. Houve ainda aumento significativo no conteúdo de cálcio na casca e no tecido medular dos tubérculos. Também Melo et al. (1995) obtiveram controle da podridão-mole pela infiltração a vácuo de $\mathrm{CaCl}_{2}$ em frutos de pimentão, com 39,8 e $39,7 \%$ de RSD, para as concentrações de 1,0 e $0,5 \%$, respectivamente. O mecanismo pelo qual o cálcio retarda o desenvolvimento das podridões pós-colheita pode ser similar ao efeito desse elemento no processo que retarda o amadurecimento e o amolecimento do fruto. Este nutriente auxilia na regularização do metabolismo dos frutos e em concentrações adequadas mantém a consistência destes, diminuindo a incidên- cia das doenças pela inibição da atividade da poligalacturonase (Conway e Sams, 1983; Conway et al., 1991; Conway et al., 1992). Chardonnet et al. (2000), trabalhando com B. cinerea em maçã, relatam o efeito direto do cálcio sobre o desenvolvimento do fungo como mecanismo de ação no controle da podridão pós-colheita, além da inibição da atividade da poligalacturonase e da diminuição da susceptibilidade do tecido do hospedeiro.

Os isolados de Rhodotorula sp. (LD19) e Pseudomonas sp. fluorescente (P2), aplicados em tomate associados com $\mathrm{CaCl}_{2}$ a $8 \%$, foram eficientes no controle da podridão-mole em tomate, atingindo RSD acima de $47 \%$ (Figura 1). Contudo, quando aplicados sem o prévio tratamento com $\mathrm{CaCl}_{2}$ os isolados LD-19 e P-2 apenas reduziram a doença em 21,2 e 4,8\%, respectivamente. A aplicação de bactérias no controle de podri- dões pós-colheita é destacada por Smilanick et al. (1996) que utilizaram um isolado avirulento de Pseudomonas syringae no controle biológico do mofo verde causado por Penicillium digitatum, reduzindo significativamente a doença em limão. Da mesma forma, um isolado de Pseudomonas cepacia foi capaz de reduzir o tamanho das lesões do mofo cinza (B. cinerea) e azul (P. digitatum), respectivamente em maçã e pêra (Janisiewicz e Roitman, 1988).

A associação de Rhodotorula sp. (LD-19) e Pseudomonas sp. fluorescente (P-2) com $\mathrm{CaCl}_{2}$ a $8 \%$ aumentou a RSD para 93,0 e 68,1\%, respectivamente (Figura 1). Este fato sugere a existência de uma possível interação sinergística entre os isolados utilizados no presente estudo com as soluções de $\mathrm{CaCl}_{2}$. Embora não tenham sido investigados quais os processos envolvidos, Wisniewski et al. (1995) citam no caso de controle do mofo cinza, que o cálcio aumentou a eficiência da levedura $C$. oleophila pelo efeito direto na germinação e metabolismo de $B$. cinerea e indiretamente por não alterar o metabolismo normal do organismo biocontrolador quando presente em altas concentrações. Em alguns estudos verifica-se que a eficiência biocontroladora de antagonistas é aumentada com a adição de $\mathrm{CaCl}_{2}$, como nos casos de Candida sp. e $P$. syringae (BioSave $110^{\circledR}$ ) controlando podridões causadas por $B$. cinerea e $P$. expansum em maçã (McLaughlin et al., 1990; Janisiewicz et al., 1998), bem como Kloeckera apiculata no controle de $B$. cinerea em maçã e Rhizopus stolonifer em pêssego (McLaughlin et al., 1992). No entanto, não foi observada interação de $K$. apiculata com $\mathrm{CaCl}_{2}$ na redução da incidência de Monilinia fructicola em pêssego (McLaughlin et al., 1992). De acordo com McLaughlin et al. (1990), a habilidade do cálcio em controlar as podridões é dependente do isolado da levedura e da concentração do $\mathrm{CaCl}_{2}$ utilizados. Melo et al. (1995) verificaram que isolado P-5 de Pseudomonas sp. fluorescente e LD-19 de Rhodotorula sp., o mesmo avaliado neste trabalho, proporcionaram $100 \%$ de controle da podridão-mole em pimentão, quando aplicados isoladamente. Contudo, não diferiram significativamente do trata- 
mento conjunto com $\mathrm{CaCl}_{2}$ a $0,5 \%$ que induziu RSDs de 73,3 e de $72,5 \%$ para os tratamentos bactéria + cálcio e levedura + cálcio, respectivamente. Estes fatos indicam que a atuação do cálcio no controle de podridões pode também depender do patógeno envolvido (Chardannet et al., 2000) e das diferenças existentes entre hospedeiro, patógeno e antagonistas utilizados no controle (Melo et al., 1995).

De modo geral, a aplicação de antagonistas associados com soluções de cálcio proporcionou uma redução considerável da podridão-mole em tomate, com destaque para a associação levedura/cálcio. De acordo com Sanhueza (1998), é preferível utilizar leveduras na proteção de frutos que serão consumidos in natura, pois esses microrganismos não são, geralmente, produtores de antibióticos, elementos considerados contaminantes químicos. Entre os principais mecanismos de ação das leveduras encontra-se a competição por nutrientes, a indução de resistência e o parasitismo (Mariano et al., 2000). A atividade biocontroladora de leveduras antagonistas depende da presença de um grande número de células antagonistas no sítio de ferimento, sendo este requerimento considerado um possível fator limitante para a formulação de um produto biológico (Droby et al., 1989). Por conseguinte, fatores que aumentem a atividade de biocontrole, tais como cálcio, podem ter um grande valor na implementação desta técnica, principalmente no manejo integrado de podridões pós-colheita.

\section{LITERATURA CITADA}

APS Biological Control Committee. Commercial biocontrol products available for use against plant pathogens. St. Paul, 2002. Disponível em: $<$ http:/ /www.oardc.ohaio-state.edu/apsbcc/ productlist.htm>. Acesso em 20 jan. 2004.
CHARDONNET, C.O.; SAMS, C.E.; TRIGIANO, R.N.; CONWAY, W.S. Variability of three isolates of Botrytis cinerea affects the inhibitory effects of calcium on this fungus. Phytopathology, v.90, n.7, p.769-774, 2000.

CONWAY, W.S.; GROSS, K.C.; BOYER, C.D.; SAMS, C.E. Inhibition of Penicillium expansum polygalacturonase activity by increased apple cell wall calcium. Phytopathology, v.78, n.8, p.1052$1055,1988$.

CONWAY, W.S.; SAMS, C.E. Calcium infiltration of Golden Delicious apples and its effect on decay. Phytopathology, v.73, n.12, p.1068-1071, 1983. CONWAY, W.S.; SAMS, C.E.; ABBOUT, J.A.; BRUTON, B.D. Postharvest calcium treatment of apple fruit to provide broad-spectrum protection against postharvest pathogens. Plant Disease, v.75, n.6, p.620-622, 1991.

CONWAY, W.S.; SAMS, C.E.; McGUIRE, R.G.; KELMAN, A. Calcium treatment of apples and potatoes to reduce postharvest decay. Plant Disease, v.76, n.4, p.329-334, 1992.

DE BOER, S.H.; ALLAN, E.; KELMAN, A. Survival of Erwinia carotovora in Wisconsin soils. American Potato Journal, v.56, p.243-252, 1979. DROBY, S.; CHALUTZ, E.; WILSON, C.L.; WISNIEWSKI, M. Characterization of the biocontrol activity of Debaryomyces hansenii in the control of Penicillium digitatum on grapefruit. Canadian Journal of Microbiology, v.35, p.794800, 1989.

ECKERT, J.W. Role of chemical fungicides and biological agents in postharvest disease control IN: WILSON, C.L.; CHALUTZ, E. (Eds.) Biological control of postharvest disease of fruits and vegetables. Kerneysville: U.S. Departament of Agriculture - Agricultural Research Service, 1991. p.14-30, (USDA - ARS, 92).

EDGINTON, L.V.; KHEW, K.L.; BARRON, G.L. Fungitoxic spectrun of benzimidazole compounds. Phytopathology, v.61, n.1, p.42-44, 1971.

JABUONSKI, R.E.; TAKATSU, A.; REIFSCHNEIDER, F.J.B. Avaliação de patogenicidade de bactérias do gênero Erwinia isoladas da batateira, tomateiro e outras plantas hospedeiras. Fitopatologia Brasileira, v.11, n.3, p.587, 1986. JANISIEWICZ, W.J.; CONWAY, W.S.; GLENN, D.M.; SAMS, C.E. Integrating biological control and calcium treatment for controlling postharvest decay of apples. HortScience, v.33, p.105-109, 1998.

JANISIEWICZ, W.J.; ROITMAN, J. Biological control of blue mold and gray on apple and pear with Pseudomonas cepacia. Phytopathology, v.78, n.12, p.1697-1700, 1988.

KUROZAWA, C.; PAVAN, M.A. Doenças das solanáceas, In: KIMATI, H.; AMORIM, L.; BERGAMIN FILHO, A.; CAMARGO, L.E.A., REZENDE, J.A.M. (Eds.). Manual de fitopatologia. São Paulo: Ceres, 1997. v.2, p.665-675.
MARIANO, R.L.R.; SILVEIRA, E.B.; GOMES, A.M.A.; RODRIGUES, V.J.L.B.; ASSIS, S.M.P. Biocontrole de doenças de plantas. IN: TORRES, J.B; MICHEREFF, S.J. (Eds.) Desafios do manejo integrado de pragas e doenças. Recife: Imprensa Universitária, 2000. p.78-111.

McGUIRE, R.G.; KELMAN, A. Reduce severity of Erwinia soft rot in potato tubers with increase calcium content. Phytopathology, v.74, n.10, p.1250-1256, 1984.

McLAUGHLIN, R.J.; WISNIEWSKI, M.E.; WILSON, C.L.; CHALUTZ, E. Effect of inoculum concentration and salts solutions on biological control of postharvest diseases of apple with Candida sp. Phytopathology, v.80, n.5, p.456461, 1990.

McLAUGHLIN, R.J.; WILSON, C.L.; DROBY, S.; BEN-ARIE, R.; CHALUTZ, E. Biological control of postharvest diseases of grape, peach and apples with the yeasts Kloeckera apiculata and Candida guiliermondii. Plant Disease, v.76, n.5, p.470-473, 1992.

MELO, R.A.G.; MARIANO, R.L.R.; MICHEREFF, S.J.; MENEZES, M.; COELHO, R.S.B. Controle biológico da podridão-mole do pimentão (Capsicum annum) causada por Erwinia carotovora subsp. carotovora. Summa Phytopathologica, v.21, n.3-4, p.206-212, 1995.

PUSEY, P.L.; WILSON, C.L. Postharvest biological control of stone fruit brown rot by Bacillus subtilis. Plant Disease, v.68, n.9, p.753-756, 1984.

SANHUEZA, R.M.V. Leveduras para o controle de fitopatógenos. In: SIMPÓSIO DE CONTROLE BIOLÓGICO, 6., 1998, Rio de Janeiro. Anais... Rio de Janeiro: FIOCRUZ, 1998. p.340-343.

SHARPLES, R.O.; JOHNSON, D.S. The influence of calcium on senescence changes in apples. Annals of Applied Biology, v.85, p.450-453, 1977.

SMILANICK, J.L.; GOWIN-BEHE, C.C.; MARGSAN, D.A.; BULL, C.T.; MACKEY, B.E. Virulence on citrus of Pseudomonas syringae strains that control postharvest green mold of citrus fruit. Plant Disease, v.80, n.10, p.1123-1128, 1996. TAKATSU, A.; MELLO, S.C.M.; GARCIA, E.S.O.B. Fruto de pimentão como meio parcialmente seletivo para isolamento de Erwinia carotovora. Fitopatologia Brasileira, Brasília, v.6, n.3, p.550-551, 1981.

XU, G.W.; GROSS, D.C. Selection of fluorescent Pseudomonads antagonistc to Erwinia carotovora amd suppressive of potato seed piece decay. Phytopathology, v.76, n.4, p.414-422, 1986.

WISNIEWSKI, M.; DROBY, S.; CHALUTZ, E.; EILAN, Y. Effects of $\mathrm{Ca}^{2+}$ and $\mathrm{Mg}^{2+}$ on Botrytis cinerea and Penicillium expansum in vitro and on the biocontrol activity of Candida oleophila. Plant Pathology, v.44, p.1016-1024, 1995. 